\title{
General Psychiatry Evaluation of paliperidone on social function in patients with chronic schizophrenia
}

\author{
Yan Gu, ${ }^{1}$ Hong Peng, ${ }^{1}$ Jingjing Dai, ${ }^{1}$ Hui Gao, ${ }^{1}$ Xianghong Yang, ${ }^{1}$ Jialing Sheng, ${ }^{1}$ \\ Chen Zhang ${ }^{2}$
}

To cite: Gu Y, Peng H, Dai J, et al. Evaluation of paliperidone on social function in patients with chronic

schizophrenia. General Psychiatry 2018;31:e000011. doi:10.1136/

gpsych-2018-000011

Received 11 April 2018 Revised 28 May 2018 Accepted 01 June 2018

Check for updates

(C) Author(s) (or their employer(s)) 2018. Re-use permitted under CC BY-NC. No commercial re-use. See rights and permissions. Published by BMJ.

${ }^{1}$ Department of Psychiatry, Shanghai Civil Affairs First Mental Health Center, Shanghai, China

${ }^{2}$ Shanghai Mental Health Center, Shanghai Jiao Tong University School of Medicine, Shanghai, China

Correspondence to

Chen Zhang;

zhangchen645@gmail.com

\section{ABSTRACT}

Background The impairment of social function is widespread in the patients with chronic schizophrenia, which seriously affects family, life and work conditions. Aims The main purpose of this study was to investigate the efficacy of paliperidone in the treatment of social function in chronic schizophrenia.

Methods A total of 81 patients who met the standard criteria for schizophrenia and long-term hospitalised inpatients were randomly divided into the treatment group and normal control group following a 1 -year prospective follow-up study. The reatment group (41 cases) used paliperidone extended-release tablets for reducing dosage, as appropriate, based on the original treatment strategy; and the control group (40 cases) used the former drugs. All patients were assessed using the Positive and Negative Symptom Scales (PANSS), and the Treatment Emergent Symptom Scale (TESS) was used to assess adverse drug reactions. The Hospitalised Psychiatric Patients' Social Functions Rating Scale (SSPI) was used to assess social function of participants before and after 8 weeks, 6 months and 1 year of treatment.

Results At baseline there were no significant differences between the two groups in age, duration of illness, educational background and dosage of antipsychotic drugs (converted into chlorpromazine equivalency). There was statistically significant difference in PANSS positive symptoms by interaction effect $\left(\mathrm{F}_{\text {groupxtime }}=18.24, \mathrm{df}=3237\right.$, $p<0.001)$ and time effect $\left(F_{\text {time }}=21.66, d f=3, p<0.01\right)$ and the difference in PANSS positive symptoms by grouping effect $\left(\mathrm{F}_{\text {group }}=0.68, \mathrm{df}=1, p=0.41\right.$ ) was not statistically significant. The difference of grouping effect of PANSS negative symptoms ( $\mathrm{F}_{\text {group }}=9.93, \mathrm{df}=1, p=0.002$ ), time effect $\left(F_{\text {time }}=279.15, \mathrm{df}=3, p<0.001\right)$ and interaction effect $\left(F_{\text {group xtime }}=279.15, \mathrm{df}=3237, p<0.001\right)$ were statistically significant. There were statistically significant differences in the grouping effect $\left(F_{\text {oroup }}=6.59, \mathrm{df}=1, p=0.012\right)$, time effect $\left(F_{\text {time }}=152.97, d f=3, p<0.001\right)$ and interaction effect $\left(F_{\text {groupxtime }}=148.82, \mathrm{df}=3237, p<0.001\right)$ of PANSS general pathological symptoms, the same as the total score of the PANSS, which showed large differences in grouping effect $\left(\mathrm{F}_{\text {oroup }}=7.04, \mathrm{df}=1, p=0.001\right)$, time effect $\left(\mathrm{F}_{\text {time }}=210.78\right.$, $\mathrm{df}=3, p<0.001)$ and interaction effect $\left(\mathrm{F}_{\text {rrounx } x \text { time }}=205.20\right.$, $\mathrm{df}=3237, p<0.01$ ). We found in the total SSPI score, grouping effect $\left(F_{\text {oroup }}=31.70, \mathrm{df}=1, p<0.001\right)$, time effect $\left(F_{\text {time }}=161.84, \mathrm{df}=3, p<0.001\right)$ and interaction effect $\left(F_{\text {oroup xtime }}=132.74, \mathrm{df}=3237, p<0.001\right)$ were demonstrated to be significantly different. Even though adverse reactions occurred 7 times in the treatment group and 44 times in the control group based on the Treatment Emergent Symptom Scale (TESS), incidence rate was significantly lower than that of the control group $\left(\chi^{2}=18.854, p<0.001\right)$. Conclusion Paliperidone can safely and effectively improve negative symptoms and social function in patients with chronic schizophrenia.

\section{BACKGROUND}

Schizophrenia is a serious mental illness, and because of its difficulty to cure and high relapse rate, chronic patients are the majority. ${ }^{1}$ Social function is a kind of psychological state in which individuals can understand others social activities and it ensures that individuals can normally and effectively participate in social activities. ${ }^{2}$ Social functioning impairment in individuals with schizophrenia is often influenced by their negative symptoms. ${ }^{3}$ Paliperidone is a new antipsychotic drug, which has been shown to be effective for the negative symptoms of schizophrenia in early clinical studies; ${ }^{4-6}$ however, it is not clear whether it can improve social function of patients with chronic schizophrenia. Therefore, the aim of this study was to evaluate the efficacy of paliperidone in improving social function in those with chronic schizophrenia.

\section{METHODS}

\section{Study participants}

The 81 participants in this study were patients with chronic schizophrenia that had been at our hospital. Inclusion criteria: (1) met diagnostic criteria for bipolar disorder according to ICD-10; (2) duration of illness $>5$ years; (3) the patient's condition was stable, with the total score of the Positive and Negative Symptoms Scale (PANSS) $\geq 70$ points; (4) hospitalised for a long period of time, the average age was over 45 years old, and informed consent was provided by patients' legal guardians. Exclusion criteria: (1) extremely agitated, impulsive and uncooperative; (2) allergic or 
have contraindication to paliperidone extended-release tablets. The enrolled participants were divided into two groups. There were 41 participants in the experiment group and their age range was $42-73$ years old, and the mean (SD) age was 56.07 (5.433) years old. The range of duration of illness was 18-33 years, the mean (SD) of duration of illness was 26.27 (5.273) years. Educational level of the participants in the treatment group was the following: 4 primary school graduates, 19 junior high graduates, 11 high school graduates and 7 college graduates. Chlorpromazine, clozapine, and perphenazine were mainly used for treatments and the average valency of drug was converted into 215.73 (51.424) $\mathrm{mg}$ /day of chlorpromazine. Forty subjects were included in the control group, the age range was $51-78$ years old with the mean (SD) age of 57.40 (4.824) years old. The range of the duration of illness was 22-34 years, and the mean (SD) duration of illness was 27.50 (3.6) months. Educational level of the participants in the treatment group was the followings: 3 primary school graduates, 15 junior high graduates, 16 high school graduates and 6 college graduates. Chlorpromazine, clozapine, perphenazine were mainly used for treatments and the average valency of drugs was converted into 214.88 (53.102) $\mathrm{mg}$ /day of chlorpromazine. There were no significant differences between the experiment group and the control group in age, duration of illness or drug comparisons.

\section{Study methods}

In this study, 81 patients were randomly divided into the treatment group and the control group according to the digital table method after being enrolled in the study. This study referred to our previous study design, ${ }^{7}$ which was a prospective cohort follow-up study (figure 1).

\section{Treatment group}

The study group initially took the antipsychotic drugs orally and the paliperidone extended-release tablets (Xian Janssen Pharmaceutical Co.) began in January 2016 for a 1-year follow-up. The dosage ranged from 3 to $6 \mathrm{mg} /$ day, with a mean (SD) dose of $4.76(1.64) \mathrm{mg} /$ day.

\section{Control group}

The control group orally took the original tablets and were followed-up for 1 year.

\section{Treatment and assessment}

The PANSS was used for the evaluation of psychiatric symptoms and the scale consisted of a total of 30 items in the Positive, Negative and General Psychopathology subscales, with a score ranging from 1 to 7 (the higher the score, the heavier the psychotic symptoms). Social Functions Rating Scale (SSPI) was used to assess the patient's social function. This scale was made up of 10 items (including occupational skills, social withdrawal, social activities, self-care and care for the people around the hospital, care and interest in the external environment) with a score ranging from 0 to 3 . The higher the score, the heavier the psychotic symptoms. The Treatment Emergent Symptom Scale (TESS), which consisted of behavioural toxicity, laboratory abnormalities, nervous system, automatic nervous system, cardiovascular system and six other aspects, was used to evaluate adverse drug reactions based on the scores, ranging from 0 to 4 (the higher the score, the more serious the adverse reactions). Two psychiatrists who had more than 3 years of clinical experience administered the tests at the end of 8 weeks, 6 months and 12 months of treatment. Rater consistency was evaluated (Kappa $=0.85-0.91$ ).

\section{Statistical methods}

SPSS V.18.0 was used for the data analysis. Discreet data were represented with cases and percentages were analysed using the $\chi^{2}$ test. Measurement data were represented with mean (SD), and repeated measures analysis of variance and t-tests were employed between the two groups. Statistical significance was set at $p<0.05$.

\section{RESULTS}

\section{General data of two groups of patients}

Both groups were treated with first-generation antipsychotic medication before admission. There were no significant differences $(p>0.05)$ in age, duration of illness, educational level and dose of antipsychotic medication (converted into chlorpromazine equivalence) between the two groups (see table 1).

Comparison of the total scores of the Positive and Negative Syndrome Scale (PANSS) and the Social Functions Rating Scale (SSPI) scores before and after treatment

Before treatment, there were no cross-group differences in PANSS dimensions, total scores and SSPI scores. There was no statistically significant difference of the PANSS positive symptoms in grouping effect $\left(\mathrm{F}_{\text {group }}=0.68, \mathrm{df}=1\right.$, $\mathrm{p}=0.41)$, but the time effect $\left(\mathrm{F}_{\text {time }}=21.66, \mathrm{df}=3, p<0.01\right)$ and the interaction effect were statistically significant

Table 1 Comparison of continuous variables (mean (SD))

\begin{tabular}{lcccl}
\hline Variable & $\begin{array}{l}\text { Treatment group } \\
(\mathbf{n}=\mathbf{4 1})\end{array}$ & Control group $(\mathbf{n}=\mathbf{4 0 )}$ & $\boldsymbol{t}$ & P values \\
\hline Age (years) & $56.07(5.433)$ & $57.40(4.824)$ & 1.161 & 0.249 \\
duration of illness (years) & $26.27(5.273)$ & $27.50(3.616)$ & 1.223 & 0.225 \\
\hline Education (years) & $10.71(2.99)$ & $11.05(2.75)$ & -0.54 & 0.59 \\
\hline Antipsychotic drug (mg) & $215.73(51.424)$ & $214.88(53.102)$ & 0.074 & 0.941 \\
\hline
\end{tabular}


$\left(\mathrm{F}_{\text {group } x \text { time }}=18.24, \mathrm{df}=3237, p<0.01\right)$. The difference of grouping effect of PANSS negative symptoms $\left(\mathrm{F}_{\text {group }}=9.93\right.$, $\mathrm{df}=1, p=0.002)$, time effect $\left(\mathrm{F}_{\text {time }}=279.15, \mathrm{df}=3, p<0.001\right)$ and interaction effect $\left(\mathrm{F}_{\text {group } x \text { time }}=279.15, \mathrm{df}=3237, p<0.01\right)$ was statistically significant. There were statistically significant differences in the grouping effect $\left(\mathrm{F}_{\text {group }}=6.59, \mathrm{df}=1\right.$, $p=0.012)$, time effect $\left(\mathrm{F}_{\text {time }}=152.97, \mathrm{df}=3, p<0.01\right)$ and interaction effect $\left(\mathrm{F}_{\text {group } \times \text { ime }}=148.82, \mathrm{df}=3237, p<0.01\right)$ of PANSS general pathological symptoms, the same as the total score of the PANSS, which showed great differences in grouping effect $\left(\mathrm{F}_{\text {group }}=7.04, \mathrm{df}=1, p=0.01\right)$, time effect $\left(\mathrm{F}_{\text {time }}=210.78, \mathrm{df}=3, p<0.01\right)$ and interaction effect $\left(\mathrm{F}_{\text {groupx- }}\right.$ time $=205.20, \mathrm{df}=3237, p<0.01)$. We found in the total score of SSPI, grouping effect $\left(\mathrm{F}_{\text {group }}=31.70, \mathrm{df}=1, p<0.01\right)$, time effect $\left(\mathrm{F}_{\text {time }}=161.84, \mathrm{df}=3, \not<0.01\right)$ and interaction effect $\left(\mathrm{F}_{\text {group } x \text { time }}=132.74, \mathrm{df}=3237, p<0.01\right)$ were demonstrated to be significantly different. The results of posthoc analysis showed that there were significant differences in the scores of the PANSS negative symptoms, psychopathological scores, total scores and total scores of SSPI in the treatment group compared with the baseline at each follow-up point, while the difference between the PANSS and the SSPI scores in the control group not statistically significant compared with the baseline period in the control group (table 2).

Comparison of the Treatment Emergent Symptom Scale (TESS) in the two groups

By the end of this study, there occurred 7 instances of side effects in the experiment group and 44 instances in the control. Therefore, the control group had significantly more cases of adverse reaction than the study group. The changes in routine blood test $\left(\mathrm{X}^{2}=6.32\right)$, tachycardia $\left(\chi^{2}=4.31\right)$, ECG $\left(\chi^{2}=4.31\right)$ and gain weight $\left(\chi^{2}=5.46\right)$ of the two groups were significantly different compared with the controls $\left(\chi^{2}=18.85, \mathrm{p}<0.001\right)$ (table 3$)$.

\section{DISCUSSION}

\section{Main findings}

This study conducted a 1-year follow-up of the patients receiving standard treatment with paliperidone and found improvement in social function compared with the control group. Paliperidone is a dopamine antagonist and 5-HT2A antagonist of the atypical antipsychotic class of medications and can be used for psychotic disorders. Although paliperidone is the active metabolite of risperidone 9-hydroxyrisperidone, previous clinical studies have shown that the pharmacological characteristics of paliperidone are not exactly the same as risperidone. ${ }^{8}$ Paliperidone has a slightly higher affinity for dopamine D1, D2, D3 and D5 receptors and a higher affinity for norepinephrine $\alpha 2$ and 5-HT7 receptors when compared with risperidone. ${ }^{9}$ The alpha 2 methadrenergic receptor in the prefrontal cortex plays an important role in the mediation of cognitive function, ${ }^{10}$ and 5 -HT7 receptor plays an important role in emotion, learning and memory and endocrine regulation. ${ }^{11}$ The high affinity of paliperidone

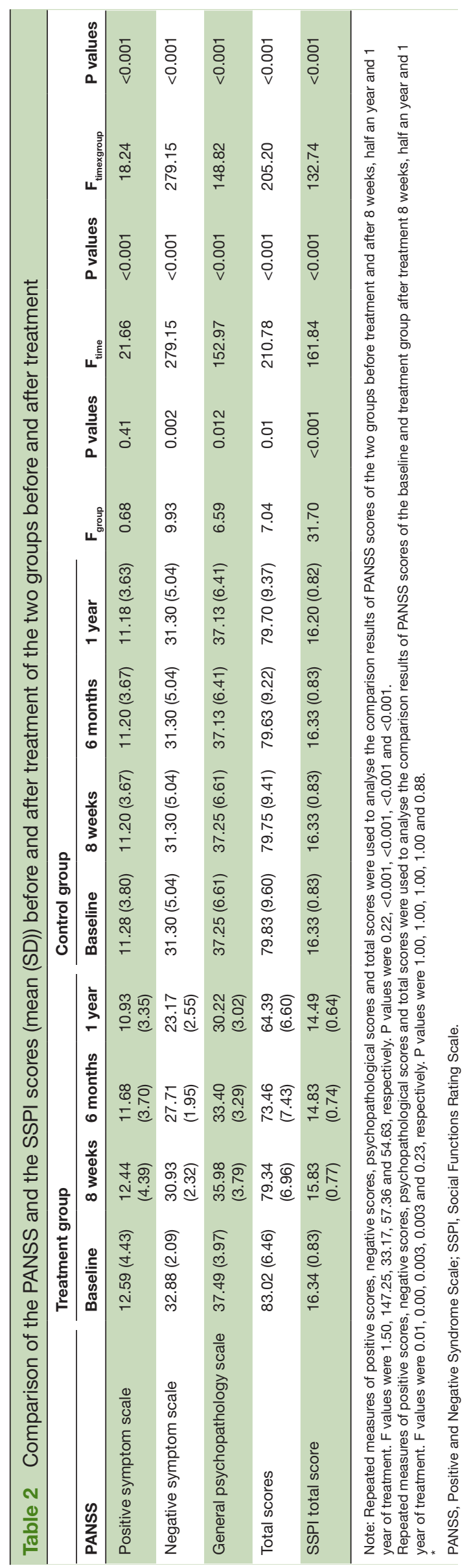




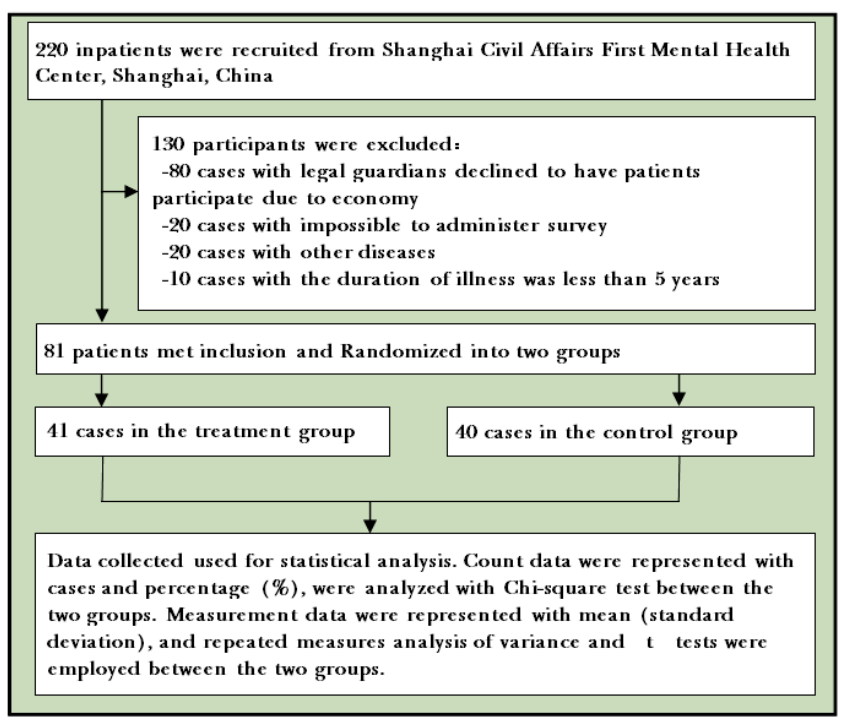

Figure 1 Flowchart of the study.

to the a-2 receptor and 5-HT7 receptor suggests that it has certain advantages in cognitive function and mood function, ${ }^{12}{ }^{13}$ while emotion and cognitive function are also important factors affecting negative symptoms and social function in patients with schizophrenia. Chronic schizophrenia patients with long-term hospitalisation have long-term separation from society, so social function can gradually regress and negative symptoms may be more prominent. Nevertheless, there are also some positive symptoms that remain persistent. In some cases, positive symptoms reappear and antipsychotics are needed for long-term treatment. In this study, the treatment group was designed to use a moderate amount of antipsychotic drugs on the basis of the appropriate amount of Paliperidone Extended-Release Tablets. Most patients used for 3-6 mg daily, which showed an effect and relieved negative symptoms while significantly improving their social and occupational abilities. Therefore, the results of this

\begin{tabular}{|c|c|c|c|c|}
\hline Variable & $\begin{array}{l}\text { Treatment } \\
\text { group } \\
(n=41)\end{array}$ & $\begin{array}{l}\text { Control } \\
\text { group } \\
(\mathrm{n}=40)\end{array}$ & $\chi^{2}$ & $\begin{array}{l}\mathbf{P} \\
\text { values }\end{array}$ \\
\hline Somnolence & 1 & 3 & 1.11 & 0.29 \\
\hline Blood abnormalities & 1 & 8 & 6.32 & 0.01 \\
\hline Abnormal liver function & 0 & 2 & 2.10 & 0.15 \\
\hline Akathisia & 2 & 6 & 2.33 & 0.13 \\
\hline Nausea and vomiting & 1 & 4 & 1.99 & 0.16 \\
\hline Tachycardia & 0 & 4 & 4.31 & 0.04 \\
\hline ECG abnormality & 0 & 4 & 4.31 & 0.04 \\
\hline Gain weight & 0 & 5 & 5.46 & 0.02 \\
\hline Headache & 0 & 1 & 1.04 & 0.31 \\
\hline Tardive dyskinesia & 2 & 7 & 3.27 & 0.07 \\
\hline Total & 7 & 44 & 18.85 & 0.00 \\
\hline
\end{tabular}

study suggest that paliperidone can effectively improve negative symptoms and social function in patients with chronic schizophrenia. However, the results of this study show that after 1 year of follow-up, the efficacy of paliperidone in the treatment of positive symptoms is similar to that of chlorpromazine, clozapine, perphenazine and other drugs. The main reason is that this study chose patients with chronic schizophrenia as the participants and their positive symptoms were stable. Therefore, the non-inferiority result is due to this floor effect.

In terms of safety evaluation and after 1 year of follow-up, the results show that the treatment group patients had a lower incidence of adverse reactions such as somnolence, sitting and delayed motor disorder, and no cases of headache, tachycardia, abnormal ECG and weight gain, suggesting that the incidence of adverse reactions in paliperidone is lower and therefore safer. Pharmacological studies have shown that the affinity of the paliperidone and 5-HT2a receptor is stronger than the D2 receptor, and the blocking action of the 5-HT2a receptor helps to relieve the patient's external conical reaction and therefore has a lower incidence of adverse reactions than traditional antipsychotic agents.

\section{Limitations}

The weakness of this research lies in the small sample size and duration of follow-up of only 1 year. These results may be limited in looking at long-term efficacy in patients with chronic schizophrenia; therefore, more in-depth research is needed. As a clinical control study, this study lacks the use of placebo in patients. The findings would be more persuasive if placebo were used in the control group.

\section{Implications}

The results of this study indicate that paliperidone can effectively improve negative symptoms in patients with chronic schizophrenia and contribute to the improvement of social function and safety. Therefore, this study suggests that paliperidone can be used as a first-line treatment for chronic schizophrenia with negative symptoms.

Contributors $Y G$ and $C Z$ were responsible for the design, statistical analysis and post-data write-up of the article. HP, JD, HG, XY and JS collected the data and undertook the scale evaluation.

Funding This study was supported in part by the National Science Fund of China $(81771450,81471358)$, Shanghai Health Bureau scientific research grant (201540029) and Shanghai Municipal Education Commission—Gaofeng Clinical Medicine Grant (20152530).

\section{Competing interests None declared.}

Patient consent Obtained.

Ethics approval This study was approved by the Ethics Committee of the Shanghai No. 1 Mental Health Center (YJZXLL201601).

Provenance and peer review Not commissioned; externally peer reviewed. Data sharing statement № additional data are available.

Open access This is an open access article distributed in accordance with the Creative Commons Attribution Non Commercial (CC BY-NC 4.0) license, which permits others to distribute, remix, adapt, build upon this work non-commercially, and license their derivative works on different terms, provided the original work is 
properly cited and the use is non-commercial. See: http://creativecommons.org/ licenses/by-nc/4.0

\section{REFERENCES}

1. Aikawa S, Kobayashi H, Nemoto $\mathrm{T}$, et al. Social anxiety and risk factors in patients with schizophrenia: relationship with duration of untreated psychosis. Psychiatry Res 2018;263:94-100.

2 Hiser J, Koenigs M. The multifaceted role of the ventromedial prefrontal cortex in emotion, decision making, social cognition, and psychopathology. Biol Psychiatry 2018;83:638-47.

3. Popolo R, Smith E, Lysaker PH, et al. Metacognitive profiles in schizophrenia and bipolar disorder: comparisons with healthy controls and correlations with negative symptoms. Psychiatry Res 2017;257:45-50.

4. Savitz AJ, Xu H, Gopal S, et al. Efficacy and safety of paliperidone palmitate three-monthly formulation in East Asian patients with schizophrenia: subgroup analysis of a global, randomized, doubleblind, Phase III, noninferiority study. Neuropsychiatr Dis Treat 2017;13:2193-207.

5. Schreiner A, Bergmans P, Cherubin P, et al. The effect of longacting paliperidone palmitate once-monthly on negative and depressive symptoms in patients with schizophrenia switched from previous unsuccessful treatment with oral aripiprazole. Ther Adv Psychopharmacol 2017;7:59-65.
6. Mauri M, Mauri MC, Adami M, et al. Efficacy and tolerability of paliperidone ER in patients with unsatisfactorily controlled schizophrenia by other antipsychotics: a flexible-dose approach. Int Clin Psychopharmacol 2015;30:329-37.

7 Zhang C, Chen MJ, Wu GJ, et al. Effectiveness of Antipsychotic Drugs for 24-Month Maintenance Treatment in First-Episode Schizophrenia: Evidence From a Community-Based "Real-World" Study. J Clin Psychiatry 2016;77:e1460-e1466.

8. Macaluso M, Oliver H, Sohail Z. Pharmacokinetic drug evaluation of paliperidone in the treatment of schizoaffective disorder. Expert Opin Drug Metab Toxicol 2017;13:871-9.

9. Zhang L, Li J, Zhao Y, et al. Critical evaluation of paliperidone in the treatment of schizophrenia in Chinese patients: a systematic literature review. Neuropsychiatr Dis Treat 2016;12:113-31.

10. Berridge CW, Spencer RC. Differential cognitive actions of norepinephrine 22 and a1 receptor signaling in the prefrontal cortex. Brain Res 2016;1641(Pt B):189-96.

11. Pytka K, Partyka A, Jastrzebska-Wiesek M, et al. Antidepressant- and Anxiolytic-Like Effects of New Dual 5- $\mathrm{HT}_{1} \mathrm{~A}$ and 5- $\mathrm{HT}_{7}$ Antagonists in Animal Models. PLoS One 2015;10:e0142499.

12. Toohey N, Klein MT, Knight J, et al. Human 5-HT7 receptor-induced inactivation of forskolin-stimulated adenylate cyclase by risperidone, 9-OH-risperidone and other "inactivating antagonists". Mol Pharmacol 2009;76:552-9.

13 Dremencov E, El Mansari M, Blier P. Distinct electrophysiological effects of paliperidone and risperidone on the firing activity of rat serotonin and norepinephrine neurons. Psychopharmacology 2007;194:63-72

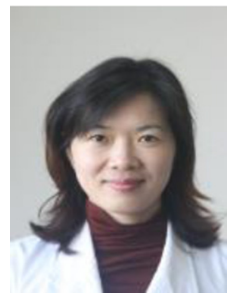

Yan Gu received a bachelor's degree from the medical college of Shanghai Jiaotong University in 2006. She has been working as a clinician at the Shanghai First Mental Health Center since 2002. In 2009, she was appointed as medical director of a unit at this hospital and later (2015) became the head of the Medical Affairs Department. She is now working as attending physician and interested in researching the diagnosis and treatment of various mental disorders. 